\title{
A new method to calculate intra-patient variability in tacrolimus concentrations.
}

Teun van Gelder ${ }^{1}$

${ }^{1}$ Leiden University Medical Center

April 6, 2021

\section{Hosted file}

commentary to BJCP 2021 00034.pdf available at https://authorea.com/users/406182/articles/ 516939-a-new-method-to-calculate-intra-patient-variability-in-tacrolimus-concentrations 